\title{
Resveratrol Inhibits Neointimal Growth after Arterial Injury in High-Fat-Fed Rodents: The Roles of SIRT1 and AMPK
}

\author{
June Guo ${ }^{a}$ Troy J. Pereirab Yusaku Moria, c Marel Gonzalez Medina ${ }^{a}$ \\ Danna M. Breen ${ }^{a}$ Prasad S. Dalvi ${ }^{a} d$ Hangjun Zhang ${ }^{a}$ Declan F. McCole \\ Michael W. McBurney ${ }^{f}$ Scott P. Heximer ${ }^{a}$ Evangelia L. Tsianig, h \\ Vernon W. Dolinsky ${ }^{b}$ Adria Giacca ${ }^{a}, i-k$ \\ aDepartment of Physiology, University of Toronto, Toronto, ON, Canada; bepartment of Pharmacology and \\ Therapeutics, Children's Hospital Research Institute of Manitoba, University of Manitoba, Winnipeg, MB, Canada; \\ 'Division of Diabetes, Metabolism and Endocrinology, Showa University School of Medicine, Tokyo, Japan; \\ ${ }^{\mathrm{d} B i o l o g y}$ Department, Morosky College of Health Professions and Sciences, Gannon University, Erie, PA, USA; \\ eDivision of Biomedical Sciences, School of Medicine, University of California, Riverside, CA, USA; fProgram in \\ Cancer Therapeutics, Ottawa Hospital Research Institute, Departments of Medicine and Biochemistry, Microbiology \\ and Immunology, University of Ottawa, Ottawa, ON, Canada; ${ }^{9}$ Department of Health Sciences, Brock University, \\ St. Catharines, ON, Canada; ${ }^{h}$ Centre for Bone and Muscle Health, Brock University, St. Catharines, ON, Canada; \\ 'Department of Medicine, University of Toronto, Toronto, ON, Canada; 'Institute of Medical Science, University of \\ Toronto, Toronto, ON, Canada; ${ }^{\mathrm{k}}$ Banting and Best Diabetes Centre, University of Toronto, Toronto General Hospital, \\ Toronto, ON, Canada
}

\section{Keywords}

Insulin resistance $\cdot$ Femoral wire injury $\cdot$ Carotid balloon injury · Restenosis

\begin{abstract}
We have shown that both insulin and resveratrol (RSV) decrease neointimal hyperplasia in chow-fed rodents via mechanisms that are in part overlapping and involve the activation of endothelial nitric oxide synthase (eNOS). However, this vasculoprotective effect of insulin is abolished in highfat-fed insulin-resistant rats. Since RSV, in addition to increasing insulin sensitivity, can activate eNOS via pathways that are independent of insulin signaling, such as the activation of sirtuin 1 (SIRT1) and AMP-activated kinase (AMPK), we
\end{abstract}

karger@karger.com www.karger.com/jvr

Karger $\stackrel{\text { ' }}{5}$

GOPEN ACCESS
(C) 2020 The Author(s)

Published by S. Karger AG, Basel

This article is licensed under the Creative Commons AttributionNonCommercial-NoDerivatives 4.0 International License (CC BYNC-ND) (http://www.karger.com/Services/OpenAccessLicense). Usage and distribution for commercial purposes as well as any distribution of modified material requires written permission. speculated that unlike insulin, the vasculoprotective effect of RSV would be retained in high-fat-fed rats. We found that high-fat feeding decreased insulin sensitivity and increased neointimal area and that RSV improved insulin sensitivity $(p<0.05)$ and decreased neointimal area in high-fat-fed rats $(p<0.05)$. We investigated the role of SIRT1 in the effect of RSV using two genetic mouse models. We found that RSV decreased neointimal area in high-fat-fed wild-type mice $(p<0.05)$, an effect that was retained in mice with catalytically inactive SIRT1 $(p<0.05)$ and in heterozygous SIRT1-null mice. In contrast, the effect of RSV was abolished in AMKPa2null mice. Thus, RSV decreased neointimal hyperplasia after arterial injury in both high-fat-fed rats and mice, an effect likely not mediated by SIRT1 but by AMPKa2.

(C) 2020 The Author(s)

Published by S. Karger AG, Basel

Adria Giacca

Department of Physiology, University of Toronto Medical Science

Building 1 Kings College Circle, Rm. 3336

Toronto, ON M5S 1A8 (Canada)

adria.giacca@utoronto.ca 


\section{Introduction}

Metabolic syndrome is defined by a cluster of abnormalities including alterations in glucose tolerance, dyslipidemia, hypertension, and central obesity [1]. Insulin resistance, which is the key characteristic of metabolic syndrome and type 2 diabetes, increases the risk for both atherosclerosis and restenosis after percutaneous revascularization interventions $[2,3]$.

Insulin has both growth-promoting and protective effects in the vasculature. For instance, high-dose insulin promotes vascular smooth muscle cell (VSMC) proliferation, but increases VSMC differentiation in vitro $[4,5]$. In vivo, we have shown that high-dose systemic insulin (5 U/day) decreases neointimal growth after arterial injury (a model of restenosis) despite increasing VSMC proliferation $[6,7]$, consistent with a prevalent vasculoprotective effect [6-11]. We have also shown that this vasculoprotective effect is mediated by endothelial nitric oxide synthase (eNOS) [11] but is greatly diminished in insulin-resistant high-fat-fed rats [6] that have low eNOS activation [12]. Therefore, alternative mechanisms to upregulate $\mathrm{NO}$ production independent of insulin or to decrease neointimal growth by pathways unrelated to insulin may be beneficial in insulin-resistant models.

Resveratrol (RSV, trans-3,5,4'-trihydroxystilbene), a polyphenol found in red wine, has cardiovascular protective effects [13], including an "anti-restenotic" effect demonstrated by us as well as others [14-22]. In chow-fed (insulin sensitive) rodents, we have shown that the effect of RSV to decrease the arterial-injury-induced neointimal hyperplasia involves the activation of eNOS [14] by mechanisms that are unclear and potentially independent of insulin. Furthermore, RSV prevents fat-induced insulin resistance in insulin target tissues $[23,24]$. Therefore, we hypothesized that the effect of RSV to decrease neointimal hyperplasia may be preserved in a rat model of high-fat diet-induced insulin resistance, where the insulin-induced activation of eNOS is impaired.

RSV can directly or indirectly activate the $\mathrm{NAD}^{+}$-dependent class III histone deacetylase sirtuin 1 (SIRT1) [25-27]. SIRT1 has been shown to deacetylate and activate eNOS [28], and whole body or smooth muscle cellspecific overexpression of SIRT1 protected mice against neointimal hyperplasia after arterial injury $[29,30]$.

SIRT1 can activate liver kinase B1 (LKB1) by deacetylation and thus activate AMP-activated kinase (AMPK) [31]. RSV can also activate AMPK independent of SIRT1 by multiple mechanisms [31-34], including an increase in AMP:ATP ratio due to mitochondrial electron trans- port chain complex III inhibition [34] and activation of CaMKII [33]. In turn, AMPK can phosphorylate and activate eNOS [35]. Endothelial-specific overexpression of constitutively active AMPKa1 decreased neointimal hyperplasia in mice [36]. AMPKa2-null mice had increased neointimal area and intimal cell proliferation after arterial injury [37]. Therefore, the objectives of the present study were: (1) to examine whether RSV decreases neointimal hyperplasia after carotid artery balloon injury in rodents fed a high-fat diet, a model where the "anti-restenotic" action of insulin is impaired, and (2) to determine the role of SIRT1 and AMPK in the action of RSV to decrease neointimal hyperplasia in this model.

To determine the role of SIRT1, we examined the effect of RSV using two genetically modified mouse models. The first model is the catalytically inactive SIRT1 mouse model. This mouse carries a point mutation (H355Y) in the SIRT1 catalytic site, which does not affect SIRT1 protein expression [38]. Since some of the effects of SIRT1 may not be due to its deacetylase activity $[39,40]$, we also used a heterozygous SIRT1-null mouse model (SIRT1 ${ }^{+-}$) carrying an allele with a truncated SIRT1 protein [41]. The heterozygous SIRT1-null mice were used because the homozygous knockout mice die postnatally due to developmental defects [41].

To determine the role of AMPK, we chose the AMPKa2-null mouse, because although supraphysiological AMPKa1 activation decreased neointimal hyperplasia [36], whole-body AMPKa2 knockout but not AMPKa1 knockout was previously found to exacerbate neointimal formation [37].

\section{Materials and Methods}

Studies were conducted according to protocols approved by the Animal Care Committee of the University of Toronto. All surgical procedures were done under general anesthesia using isoflurane. Analgesic (Buprenorphine) was given at the onset of each surgical procedure. Male animals were studied as they were the models previously used by our group to investigate the effect of insulin [6-11] and RSV [14] since estrogen affects neointimal growth [42].

\section{Rat Studies}

Four groups of Sprague-Dawley rats (Charles River) initially weighing 400-450 g were subjected to the following treatments: (1) vehicle control treatment and a normal-fat control diet (NFC; Dyets, Bethlehem, PA, USA, Dyets No: 100741, 12\% calories from fat as corn oil); (2) vehicle control treatment and a high-fat diet (HFC; Dyets No. 100742, same protein and micronutrient composition as the normal-fat diet, $60 \%$ calories from fat obtained from beef tallow in addition to the corn oil); (3) RSV treatment (4 mg/kg per day s.c., a dose we previously found to be effective at decreasing 
neointimal area in chow-fed rats [14]; Sigma) and a normal-fat diet (NFR); and (4) RSV treatment and a high-fat diet (HFR). RSV dissolved in polyethylene glycol-300 and DMSO (9:1) or the respective vehicle was delivered subcutaneously via an osmotic pump (Alzet; Durect Corp., Cupertino, CA, USA). The implantation of osmotic pumps was performed two days after the diet onset and three days before carotid artery balloon injury, as described previously [14].

\section{Rat Carotid Artery Balloon Injury}

Injury to the left common carotid artery was performed as previously described [8].

\section{Hyperinsulinemic-Euglycemic Clamp}

To assess the effect of RSV on insulin sensitivity, hyperinsulinemic-euglycemic clamp was performed in pre-cannulated rats that did not receive arterial injury. This is the gold standard measure of insulin sensitivity and is based on the principle that in order to counteract the glucose-lowering effect of a fixed dose of insulin, a variable glucose infusion is required, higher when the subject is more insulin sensitive. Vessel cannulation (carotid artery for blood sampling and jugular vein for insulin/glucose infusion) was performed three days before the clamp procedure, as described previously [7]. After an overnight fast, a fixed rate of insulin (Humulin $\mathrm{R}, 5 \mathrm{mU} / \mathrm{kg}$ per min) was initiated through the jugular vein and maintained for $2 \mathrm{~h}$. Blood samples were taken every $5 \mathrm{~min}$ for measuring plasma glucose levels on an Analox rapid Analyzer in order to determine the rate of glucose to be infused to maintain basal glycemia. As indicated above, the rate of glucose infusion represents insulin sensitivity.

Blood Pressure Analysis

The systolic blood pressure was measured indirectly via the tail-cuff technique (Visitech BP-2000 Blood Pressure Analysis System, Apex, NC, USA). Blood pressure was measured before treatment and at 4, 14, and 28 days after arterial injury.

\section{Mouse Studies}

To address the role of SIRT1 in RSV's effect, we used two genetic mouse models on different genetic backgrounds: (1) the catalytically inactive SIRT1 homozygous mice $\left(\mathrm{SIRT} 1^{\mathrm{Y} / \mathrm{Y}}\right.$ on Sv129xCD1 background) [38] and their wild-type littermate controls and (2) the heterozygous SIRT1-null mice (SIRT1 ${ }^{+/}$on Sv129 background) [41] and their wild-type littermate controls. As mentioned in the Introduction, heterozygous mice were used since the homozygous knockout mice die postnatally due to developmental defects [41]. A portion of the SIRT1 ${ }^{\mathrm{Y} / \mathrm{Y}}$ also dies postnatally but most do survive to adulthood [38]. To address the role of AMPK in the effect of RSV, we used whole-body AMPKa2-null mice (on C57BL/6 background) and wild-type controls. All three genetically modified mouse models display exacerbated insulin resistance on a high-fat diet [43-45]. The mice were fed a high-fat diet (Dyets No. 101920, 23\% protein, 14\% carbohydrate, and 60\% fat mainly from hydrogenated coconut oil) or a $0.0375 \%$ RSV-supplemented high-fat diet (Dyets No. 182110) starting from 6 weeks of age and were maintained on their respective diets for the rest of the treatment period. Similar diets [16] have been previously used in mice where similar RSV doses ( $\sim 36 \mathrm{mg} / \mathrm{kg}$ per day) have been found effective to decrease neointimal growth by us and other authors $[14,16]$.

The Effects of Resveratrol in Rodent

Models of Restenosis
Mouse Femoral Wire Injury

Mice underwent wire injury of the femoral artery at 7 weeks of age and 5 days after the onset of diets. Wire injury was performed as described previously [14] with the following modifications: (1) In the SIRT $1^{\mathrm{Y} / \mathrm{Y}}$ and the AMPKa2-null and their controls, reinsertion of the wire was performed two more times for $1 \mathrm{~min}$ each. This was performed to ensure complete removal of the endothelium as mice were bigger than those used in the previous study [14]. (2) In the heterozygous SIRT1-null and littermate controls, one passage of the wire with $1 \mathrm{~min}$ wait time, as in the previous study, was enough to denude the artery [14].

\section{Blood and Vessel Sample Collection}

Blood glucose was monitored throughout the treatment using a glucometer (OneTouch; LifeScan Inc.) and measured at the same time of the day ( 10:00 a.m.). These values were converted to plasma glucose assuming a normal hematocrit. At 28 days after arterial injury, rats or mice were anesthetized with a cocktail of ketamine:xylazine:acepromazine (87:1.7:0.4 mg/mL, $1 \mu \mathrm{L} / \mathrm{g}$ body weight) to obtain blood samples via cardiac puncture for metabolic parameter analysis. Thereafter, the animals were euthanized by anesthetic overdose. The blood vessels were perfusion-fixed for 4 min (rats) or $15 \mathrm{~min}$ (mice) with 10\% neutral buffered formalin at physiological pressure $(110-120 \mathrm{~mm} \mathrm{Hg})$. The vessels were removed, immersed in formalin for $24-48 \mathrm{~h}$, embedded in paraffin, and divided into two blocks by cutting the midsection of the artery. Cross sections were taken from the midsection.

\section{Histomorphometric Analysis}

Intimal and medial cross-sectional areas were measured on hematoxylin and eosin-stained slides (rats) or elastic Van Giesonstained slides (mice) and analyzed using a computer-assisted morphometric system (NIS-Elements BR 3.0; Nikon Corporation). Intimal area was measured as the area encompassed by the internal elastic lamina minus the lumen area and was calculated as the average of two separate cross sections $12 \mu \mathrm{m}$ apart. Medial area was measured as the area encompassed by the external elastic lamina subtracted by the area enclosed by the internal elastic lamina and was not different among treatments.

\section{Immunohistochemistry}

Phosphorylated eNOS (p-eNOS) and phosphorylated vasodilator-stimulated phosphoprotein (p-VASP) were determined using anti-p-eNOS antibody (1:50; Santacruz, CA, USA) and pVASP antibody (1:50; Abcam, ON, Canada), as described previously [46]. Immunostaining-positive area was quantified with Image J software (U.S. National Institutes of Health, MD, USA). p-eNOS-positive area was limited to the luminal surface, whereas p-VASP-positive area was observed both in the neointima and media. Therefore, changes in p-eNOS and p-VASP were evaluated as p-eNOS-positive area/lumen length and p-VASP-positive area/ whole vascular wall area, respectively.

\section{Western Blot Analysis}

Frozen aorta collected at the end of the hyperinsulinemic clamp in rats was homogenized and processed as in our previous studies $[11,12,14]$. Protein concentration was measured by the Bradford assay using bovine serum albumin as a standard. Protein samples $(50 \mu \mathrm{g})$ were separated on a $10 \%$ sodium dodecyl sulfatepolyacrylamide gel electrophoresis (SDS-PAGE) gel, transferred 
to a nitrocellulose membrane, and analyzed with anti-SIRT1 (1:500), anti-phospho (Thr172) AMPK (1:500), anti-total AMPK $(1: 1,000)$, anti-phospho (Ser79) acetyl-CoA carboxylase (ACC) $(1: 1,000)$, anti-total ACC $(1: 1,000)$, anti-phospho eNOS (1:500), anti-total eNOS (1:500), anti-phospho (Ser473) Akt (1:1,000), anti-total Akt $(1: 1,000)$, anti-total IкBa $(1: 1,000)$, and anti-tubulin $(1: 5,000)$. All primary antibodies were purchased from Cell Signaling Technology. Secondary antibodies were from Santa Cruz Biotechnology.

\section{Plasma Assays}

Since animals were not fasted before sacrifice, metabolic parameters were obtained in the random fed state, which is the physiological state under which the injured vessels of rodents develop neointimal hyperplasia. Fasting insulin and glucose were measured in rats undergoing the hyperinsulinemic clamp. Plasma insulin was determined by radioimmunoassay (Linco Research Inc., St. Charles, MO, USA). Plasma free fatty acids (Wako, Osaka, Japan) and plasma triglycerides (Roche Diagnostic, Indianapolis, IN,
Fig. 1. The effect of resveratrol (RSV) on plasma glucose, plasma insulin, and wholebody insulin sensitivity in rats treated with normal- or high-fat diet. Plasma glucose (a) and insulin (b) levels throughout the $2 \mathrm{~h}$ hyperinsulinemic-euglycemic clamp. Whole-body insulin sensitivity is indicated by the glucose infusion rate (GINF) during the $2 \mathrm{~h}$ hyperinsulinemic-euglycemic clamp (c). NFC, normal-fat control; HFC, high-fat control; NFR, normal-fat with RSV; HFR, high-fat with RSV. Numbers in parentheses represent rat number. ${ }^{* * *} p<$ 0.001 HFC versus NFC, ${ }^{\S} p<0.05$ HFC versus HFR (post hoc Bonferroni's test after a significant interaction was found between diet and RSV, analysis performed on the last $30 \mathrm{~min}$ ).
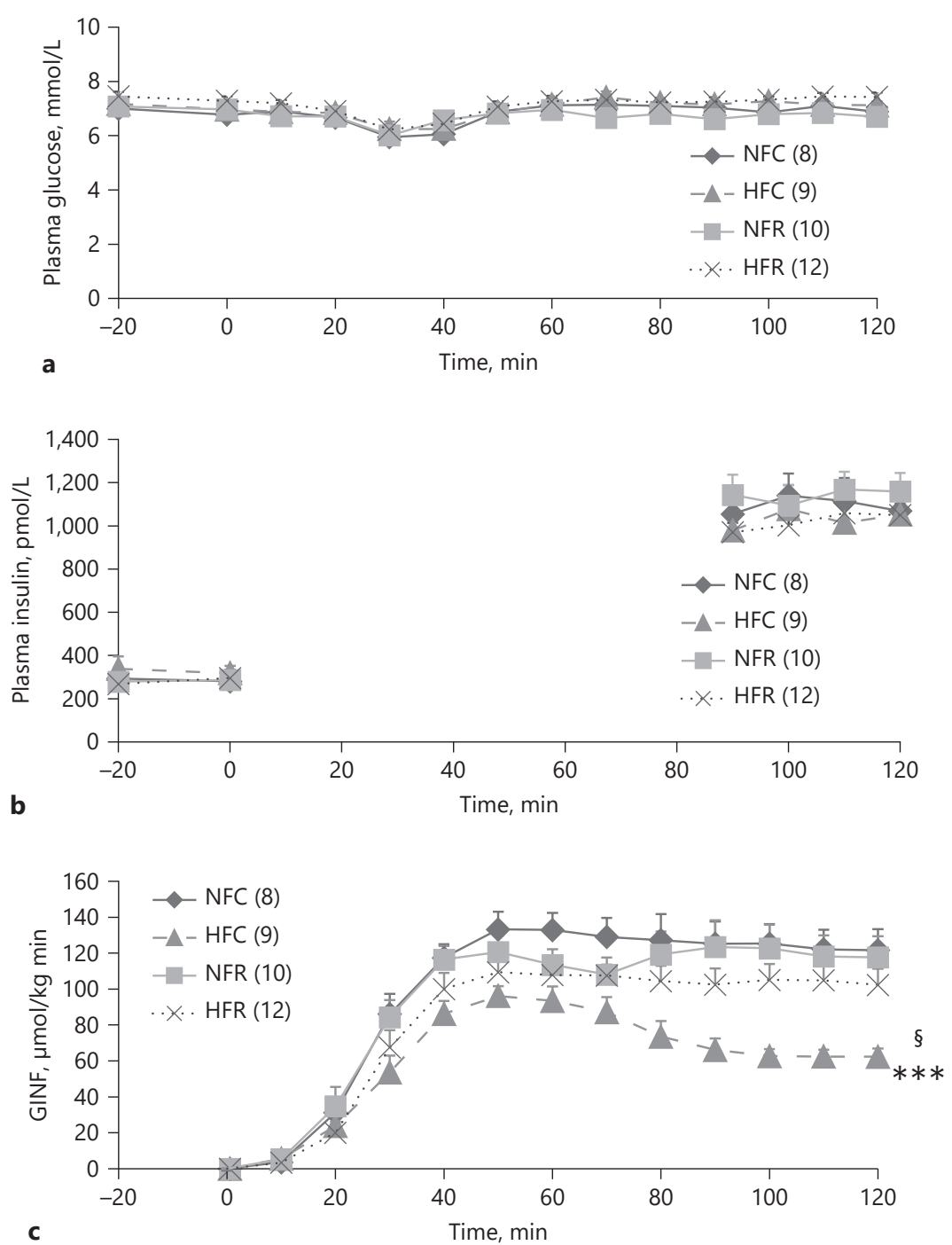

C
Fig. 2. The effect of resveratrol (RSV) on neointimal area in rats fed a normal- or high-fat diet. Representative images $(\times 40)(\mathbf{a})$ and quantification of neointimal area (b) of carotid artery cross sections measured 28 days after balloon injury from normal-fat- and high-fat-fed rats treated with RSV or vehicle. Arrows point to in- ternal elastic lamina. NFC, normal-fat control; HFC, high-fat control; NFR, normal-fat with RSV; HFR, high-fat with RSV. Numbers in parentheses represent rat number. ${ }^{* * *} p<0.001$ HFC versus NFC, ${ }^{\S \S} p<0.01$ HFC versus HFR (post hoc Bonferroni's test after a significant interaction was found between diet and RSV).

(For figure see next page.) 


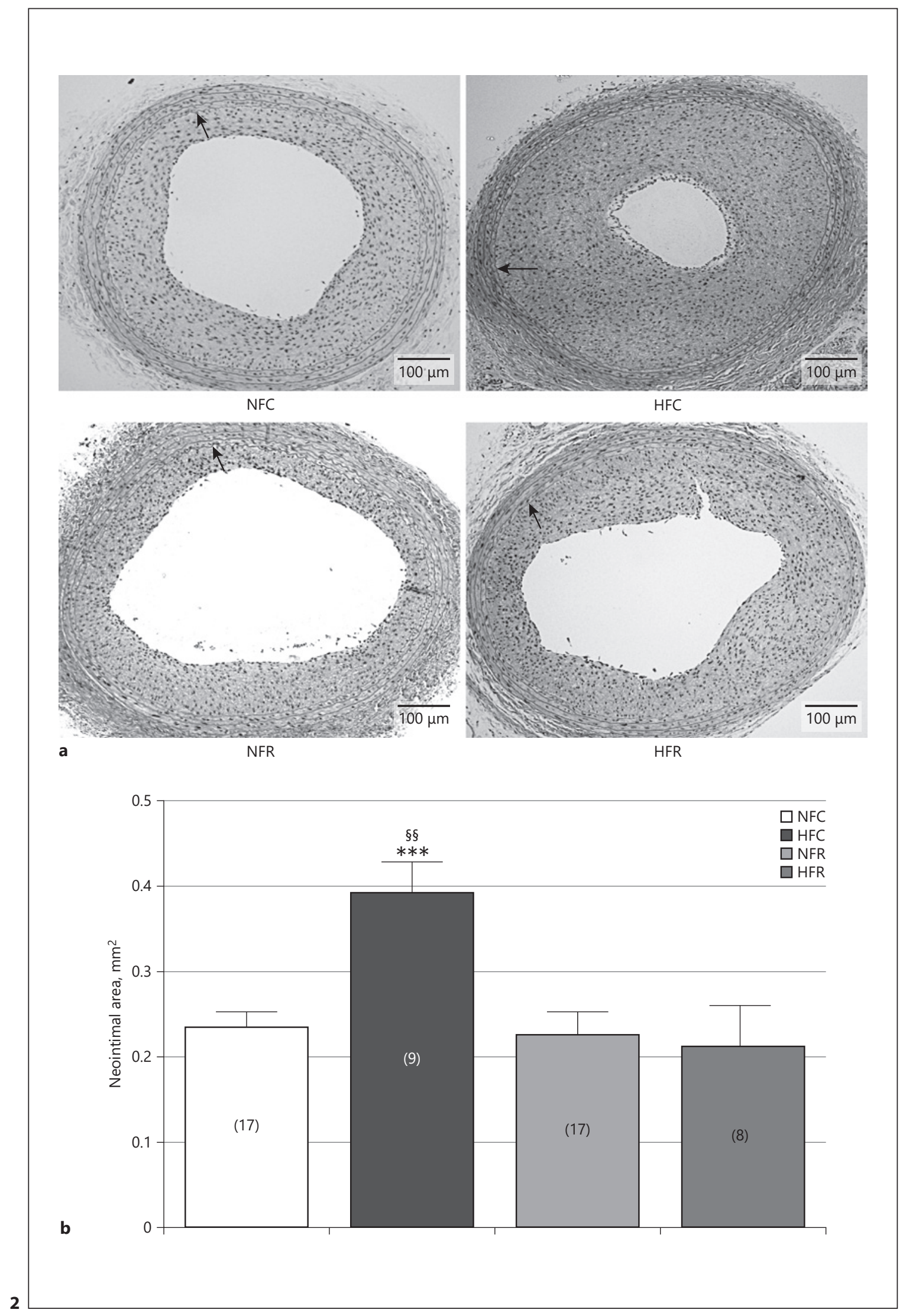


USA) were measured using colorimetric kits. Plasma NO was determined as total nitrates + nitrites via a colorimetric assay kit (QuantiChrom Nitric Oxide Assay kit; BioAssay Systems, MA, USA).

\section{Statistical Analysis}

Two-way ANOVA (diet and RSV status for rats, and genotype and RSV status for mice) with interaction was used, followed by post hoc Bonferroni's test. Statistical calculations were performed using GraphPad Prism 5.0. Data were expressed as the mean \pm SEM. Significance was accepted at $p<0.05$.

\section{Results}

As expected, high-fat-fed rats gained more weight than normal-fat-fed rats (see online suppl. Table 1; see www.karger.com/doi/10.1159/000509217 for all online suppl. material). RSV (4 mg/kg per day s.c.) did not affect weight gain. No significant difference was found in fed plasma glucose (online suppl. Table 1) or fed plasma insulin, triglyceride, and free fatty acid levels (online suppl. Table 2).

Since hypertension is a risk factor for restenosis [47] and studies have shown that RSV can decrease blood pressure [48], blood pressure was measured. Systolic blood pressure was not significantly different between the high-fat- and the normal-fat-fed groups (online suppl. Fig. 1). RSV did not affect blood pressure in either diet groups.

Because RSV has insulin-sensitizing effects, wholebody insulin sensitivity was assessed using the hyperinsulinemic-euglycemic clamp protocol. Glucose and insulin levels did not differ among groups (Fig. 1a, b). As expected, high-fat feeding impaired insulin sensitivity (the glucose infusion rate necessary to maintain the clamp) compared to normal-fat feeding (main effect of diet $p<0.001$ ), and there was a significant diet and RSV treatment interaction ( $p<0.05$ ), showing that the effect of high-fat feeding was inhibited with RSV treatment (Fig. 1c). These results are in agreement with the findings of previous studies showing that RSV improves fat-induced insulin resistance $[23,24]$. Despite the high-fat diet-induced insulin resistance found with the sensitive hyperinsulinemic-euglycemic clamp method, fasting (and postprandial) plasma insulin levels were not significantly different in rats fed a normal-fat diet compared to the high-fat diet, consistent with a previous study, where we used the same short-term feeding regimen in rats [6].

Analysis of the cross-sectional area of the injured carotids showed that high-fat diet significantly increased $(p<0.05)$ and RSV decreased neointimal area $(p<0.01)$. Importantly, there was a significant interaction between diet and RSV $(p<0.01)$, indicating that RSV counteracted the effect of fat (Fig. 2). Thus, RSV decreased neointimal formation in high-fat-fed insulin-resistant rats, whereas it did not appear to be effective in normal-fat-fed rats.

Previous studies by our group and others have shown that RSV affects SIRT1 expression and the phosphorylation (marker of activation) of AMPK and eNOS. Western blots of uninjured aorta obtained at the end of the hyperinsulinemic clamp showed that high-fat diet decreased SIRT1 expression and the phosphorylation of AMPK and of its target ACC, effects prevented by RSV. Unexpectedly, high-fat diet did not decrease eNOS phosphorylation. Although the ratio between p-eNOS and total eNOS (eNOS phosphorylation) was not significantly increased, p-eNOS (p-eNOS/tubulin) was increased by RSV (main effect $p<0.001)$. High-fat diet impaired insulin signaling and increased the activity of the inflammatory kinase IKK $\beta$, as indicated by the decreased phosphorylation of Akt and the decreased total I $\mathrm{B} B \alpha$ (degraded after phosphorylation by IKK $\beta$ ). RSV restored Akt phosphorylation and IкBa levels (Fig. 3).

In injured carotids, immunohistochemistry revealed that RSV increased p-eNOS and p-VASP $(p<0.01)$, which is a downstream molecule of the NO/cGMP signaling pathway, and high-fat diet decreased p-VASP $(p<0.05)$ (online suppl. Fig. 2). There was no significant interaction between RSV and diet. We also measured plasma NO levels. Although plasma NO tended to be decreased by highfat diet and to be increased by RSV in normal-diet-fed rats, these differences were not significant (online suppl. Table 3).

In order to examine the role of SIRT1 in the effect of RSV to decrease neointimal formation in high-fat-fed conditions, we first examined the effect of RSV in highfat-fed SIRT $1^{\mathrm{Y} / \mathrm{Y}}$ mice that have a catalytically inactive

Fig. 3. Western blots of aorta obtained from rats fed a normal- or high-fat diet. a-f Representative images and quantifications of Western blots of uninjured aorta at the end of the hyperinsulinemic clamp in rats. Y axes represent densitometric ratios, normalized to control. NFC, normal-fat control; HFC, high-fat control; NFR, normal-fat with RSV; HFR, high-fat with RSV. P-protein, phosphorylated protein, T-protein, total protein. See text for protein abbreviation. a, b, c, e, f: $n=6 /$ group; d: $n=8$ /group. The representative eNOS blots were cut and pasted from the same blot because they were accidentally arranged out of order. ${ }^{*} p<0.05$, ${ }^{* *} p<0.01 \mathrm{HFC}$ versus NFC, ${ }^{\S \S} p<0.01,{ }^{\S \S} p<0.001$ HFC versus HFR, ${ }^{\#} p<0.05$ NFR versus NFC (post hoc Bonferroni's test after a significant main effect or interaction was found).

(For figure see next page.) 

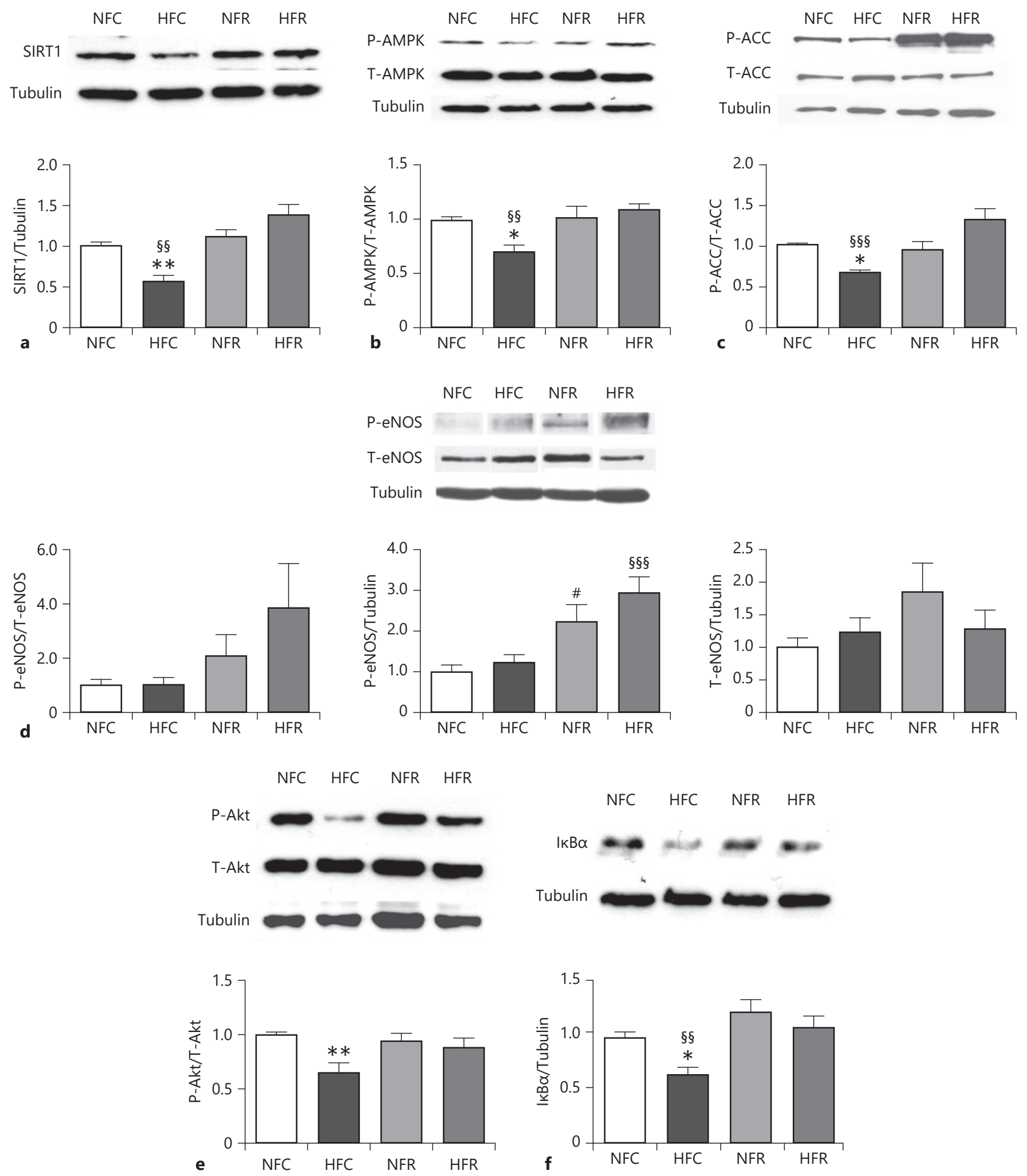


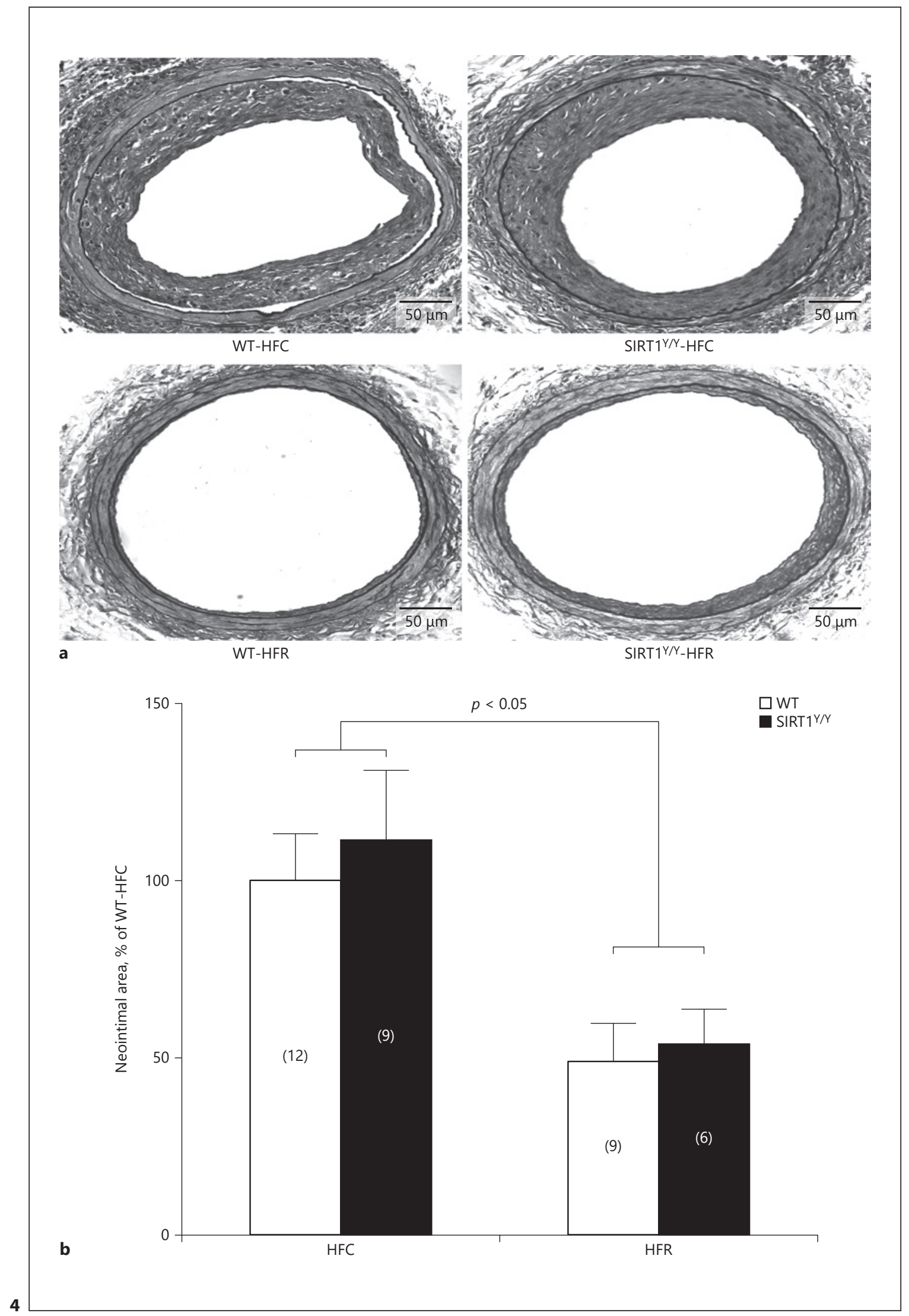

(For legend see next page.) 
SIRT1 and in their high-fat-fed wild-type controls. RSV did not significantly affect weight gain and fed plasma glucose (online suppl. Table 4$)$. RSV ( $36 \mathrm{mg} / \mathrm{kg}$ per day orally) significantly decreased neointimal area, and there was no interaction between genotype and RSV treatment, showing that RSV decreased neointimal formation irrespective of genotype (Fig. 4).

Since SIRT1 may have effects that are independent of its catalytic function $[39,40]$, we also examined the effect of RSV in high-fat-fed heterozygous mice with a truncated SIRT1 protein $\left(\mathrm{SIRT}^{+/-}\right)$, as homozygous SIRT1 knockout is lethal [41], and their high-fat-fed wild-type controls. No significant differences were found in weight gain and fed plasma glucose levels between groups (online suppl. Table 5). Again, RSV decreased neointimal area in both SIRT ${ }^{+/-}$and controls, that is, irrespective of genotype (Fig. 5). Collectively, our data of Figures 4 and 5 show that neither inactivation nor deletion of one copy of SIRT1 diminished the effect of RSV.

RSV is an established activator of AMPK and to examine the role of AMPK in the observed effects of RSV, we used AMPKa2-null mice. No significant differences were found in weight gain between high-fat-fed AMPKa2-null and wild-type mice (online suppl. Table 6). Fed plasma glucose levels were also not different between AMPKa2null and wild-type mice, similar to the two other mouse models. However, all three genetically modified models display abnormalities in glucose homeostasis when challenged by tolerance tests [43-45]. In contrast with the two models of SIRT1 inhibition used, in AMPKa2-null and wild-type mice, the effect of RSV showed a positive interaction with genotype $(p<0.05)$. Indeed, RSV decreased neointimal area only in wild-type controls, and its effect was abolished in AMPKa2-null mice (Fig. 6).

In injured femoral arteries, immunohistochemistry showed that RSV significantly increased p-eNOS in SIRT $1^{\mathrm{Y} / \mathrm{Y}}$ mice with catalytically inactive SIRT1 and their controls $(p<0.01)$ (online suppl. Fig. 3). RSV effect on peNOS was not significant in SIRT $1^{+/-}$mice $(p=0.06)$ or AMPKa2-null mice and their respective controls. RSV

Fig. 4. The effect of resveratrol (RSV) on neointimal area in mice expressing a catalytically inactive SIRT1 and wild-type controls. Representative images $(\times 200)(\mathbf{a})$ and quantification of neointimal area (b) of femoral artery cross sections measured at 28 days after wire injury in genetically modified mice expressing catalytically inactive SIRT1 protein $\left(\mathrm{SIRT}^{\mathrm{Y} / \mathrm{Y}}\right)$ or wild-type (WT) littermates (Sv129xCD1 background) fed either high-fat diet (HFC) or RSVsupplemented high-fat diet (HFR). Numbers in parentheses represent mouse number. A main effect of RSV $(p<0.05)$ was found.

The Effects of Resveratrol in Rodent Models of Restenosis had no significant effect on p-VASP in any of the three groups (online suppl. Fig. 3). Plasma NO appeared to differ by mouse genetic background since it was higher in AMPKa2-null mice and their wild-type controls (C57BL/6 background) than in SIRT1 $1^{\mathrm{Y} / \mathrm{Y}}$ mice or SIRT1 ${ }^{+/-}$mice and their wild-type controls (Sv129xCD1 and Sv129 background, respectively). However, plasma NO was not significantly affected by RSV in any of the three groups (online suppl. Table 7).

\section{Discussion}

We have previously shown that insulin decreases neointimal area after arterial injury in an eNOS-dependent manner [11]. However, the vasculoprotective effect of insulin is greatly diminished in rats fed a high-fat diet [6]. Therefore, activating mechanisms that bypass vessel insulin resistance at the level of eNOS or are unrelated to insulin action may benefit patients with insulin resistance. In insulin-sensitive chow-fed rodents, we have shown that RSV decreases neointimal area in an eNOSdependent manner [14], and previous studies have shown that RSV can increase insulin sensitivity in high-fat-fed mice [23]. Therefore, RSV may be more effective under high-fat feeding than normal-fat feeding conditions. One study in female mice has shown that RSV was effective at decreasing neointimal area after high-fat feeding by an estrogen receptor-mediated NOS-dependent mechanism [16]; however, the effects of RSV in high-fat- versus normal-fat-fed conditions were not compared. The present study in male rodents demonstrated that (1) unlike insulin, RSV effect to decrease neointimal area is more evident under conditions of high-fat than normal-fat diet in rats, and (2) RSV decreases neointimal area in high-fat-fed mice by a mechanism that is not mediated by the catalytic activity of SIRT1 and does not appear to involve transcriptional co-regulation by SIRT1 or eNOS activation but is dependent on AMPKa2.

The doses of RSV used were based on our previous studies in rats and mice [14]. After oral administration, the bioavailability of RSV is low (therefore higher oral than s.c. doses are needed); however, some of the metabolites of RSV are bioactive and may contribute to its effect [49]. We have previously shown that much higher doses given i.v. to rodents [24] yield RSV concentrations achievable by oral supplementation in humans [50].

In the present study, the effect of RSV to decrease neointimal area was not evident in rats fed a normal-fat diet, in contrast to a significant protective effect demonstrated 


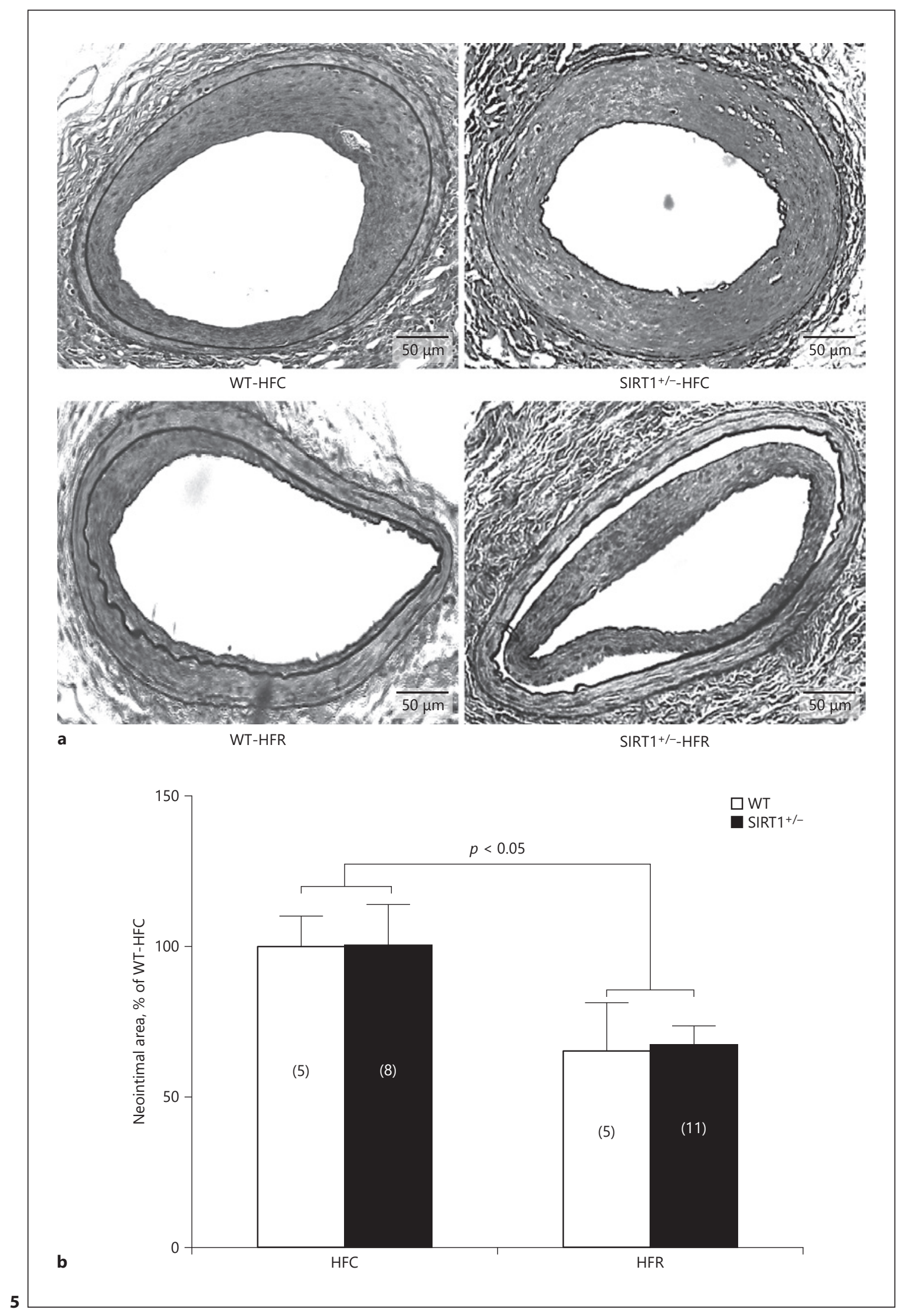

(For legend see next page.) 
in a previous study using chow-fed rats [14]. This discrepancy could be attributed to several factors. For instance, the normal-fat diet used in the present study contained $12 \%$ fat by calories, whereas the chow-diet used in the previous study contained $18 \%$ fat by calories [14]. Hence, the higher fat content may have magnified the effect of RSV on neointimal formation in the past study. In addition, different individuals performed the balloon arterial injuries in the two studies. Similarly, since the implantation surgery of osmotic pumps was also conducted by two investigators, the absorption rate of RSV from the subcutaneous tissue may have been different. Nevertheless, the current study shows that high-fat feeding accentuates (or unmasks) the effect of RSV to decrease neointimal growth, in parallel with the SIRT1 and AMPK activating, insulin sensitizing (Akt activation), and anti-inflammatory ( $\mathrm{I} \mathrm{B} \alpha$ increase) effects of RSV. Our previous study in injured carotids collected at the end of a hyperinsulinemic clamp did not show decreased AMPK activation in high-fat-fed rats; however, a decrease in AMPK activation may have been masked by the increase induced by injury [12]. The significant decrease in p-Akt in high-fat-fed rats is consistent with the tendency observed in our previous study, where vessel collection was also conducted under hyperinsulinemic conditions [12], unlike a study by other authors where uninjured aorta was collected under basal normoinsulinemic conditions, that is, in the absence of insulin stimulation [51]. In contrast to the latter study [51] that used a longer-term high-fat diet and to our previous study in injured carotids [12], we failed to show a significant decrease in eNOS activation by high-fat diet. Additionally, in the present study, RSV increased p-eNOS in uninjured aorta collected during hyperinsulinemia, consistent with another paper, where we evaluated the effect of RSV in injured carotids collected under basal normoinsulinemic conditions [14].

Since eNOS activation may be affected by injury and vessel type in addition to the experimental setting at the time of vessel collection, we also performed immunohistochemistry of the injured vessels. We found that $\mathrm{p}$ VASP, but not $\mathrm{p}$-eNOS was decreased by high-fat diet in

Fig. 5. The effect of resveratrol (RSV) on neointimal area in heterozygous SIRT1-null and wild-type controls. Representative images $(\times 200)(\mathbf{a})$ and quantification of neointimal area (b) of femoral artery cross-sections measured at 28 days after wire injury in heterozygous SIRT1-null $\left(\mathrm{SIRT}^{+/-}\right)$or wild-type (WT) littermates (Sv129 background) fed either high-fat diet (HFC) or RSV supplemented high-fat diet (HFR). Numbers in parentheses represent mouse number. A main effect of RSV $(p<0.05)$ was found. injured carotids collected under basal normoinsulinemic conditions. Thus, the high-fat diet-induced decrease in p-eNOS in injured carotids found in our previous paper may be due to collection of the injured vessels during hyperinsulinemia [12]. In addition, RSV increased p-eNOS and p-VASP irrespective of diet. Regardless of the marker of eNOS activation or activity and the vessel tested, the effect of RSV on the eNOS marker did not correlate with the effect of RSV on neointimal growth, suggesting that other mechanisms may underlie, at least in part, the beneficial effect of RSV to decrease neointimal growth under high-fat-fed conditions. Under normal-fat-fed conditions, eNOS activation by RSV was apparently not enough to decrease neointimal growth in the present study in contrast to our previous findings [14]. Notably, our findings regarding the effect of RSV on eNOS are inconsistent with this effect being mediated only by AMPK, as AMPK phosphorylation did not increase in normal-fat-fed rats.

Since in the present study RSV did not appear to have a significant effect under normal-fat feeding conditions, we focused on the mechanism of its effect under high-fat feeding conditions. Using genetic mouse models, the current study found that the effect of RSV to decrease neointimal area in the high-fat-fed mice was not mediated by the catalytic activity of SIRT1. We found that the effect of RSV is likely also not mediated via other effects of SIRT1. However, we cannot rule out that the non-deacetylasemediated effects of the single copy of SIRT1 may be mediating RSV action. It is also possible that chronic inhibition of SIRT1 in these mouse models elevates compensatory pathways, which diminish the role of SIRT1 in neointimal formation. Nevertheless, our present results indicate that the effect of RSV to decrease neointimal area is likely not mediated by SIRT1 but by AMPK since the effect of RSV was abolished in AMPKa2-null mice.

The effect of RSV on neointimal growth correlated with its effect on p-eNOS only in mice with catalytically inactive SIRT1 and their controls but did not correlate with its effect on p-eNOS, p-VASP, or plasma NO in the other groups. In particular, AMPKa2-null mice and controls showed a marked difference in the effect of RSV on neointimal growth without any difference in the effect of RSV on eNOS activation markers. Thus, our results are consistent with another mechanism of AMPK-mediated effect of RSV on neointimal growth than eNOS activation. The limitation of our mouse study is that we did not perform vessel injury in mice fed a normal-fat diet; therefore, we could not correlate the effect of RSV on eNOS activation with that on neointimal growth in the absence of high-fat feeding. Also, because this study was focused 


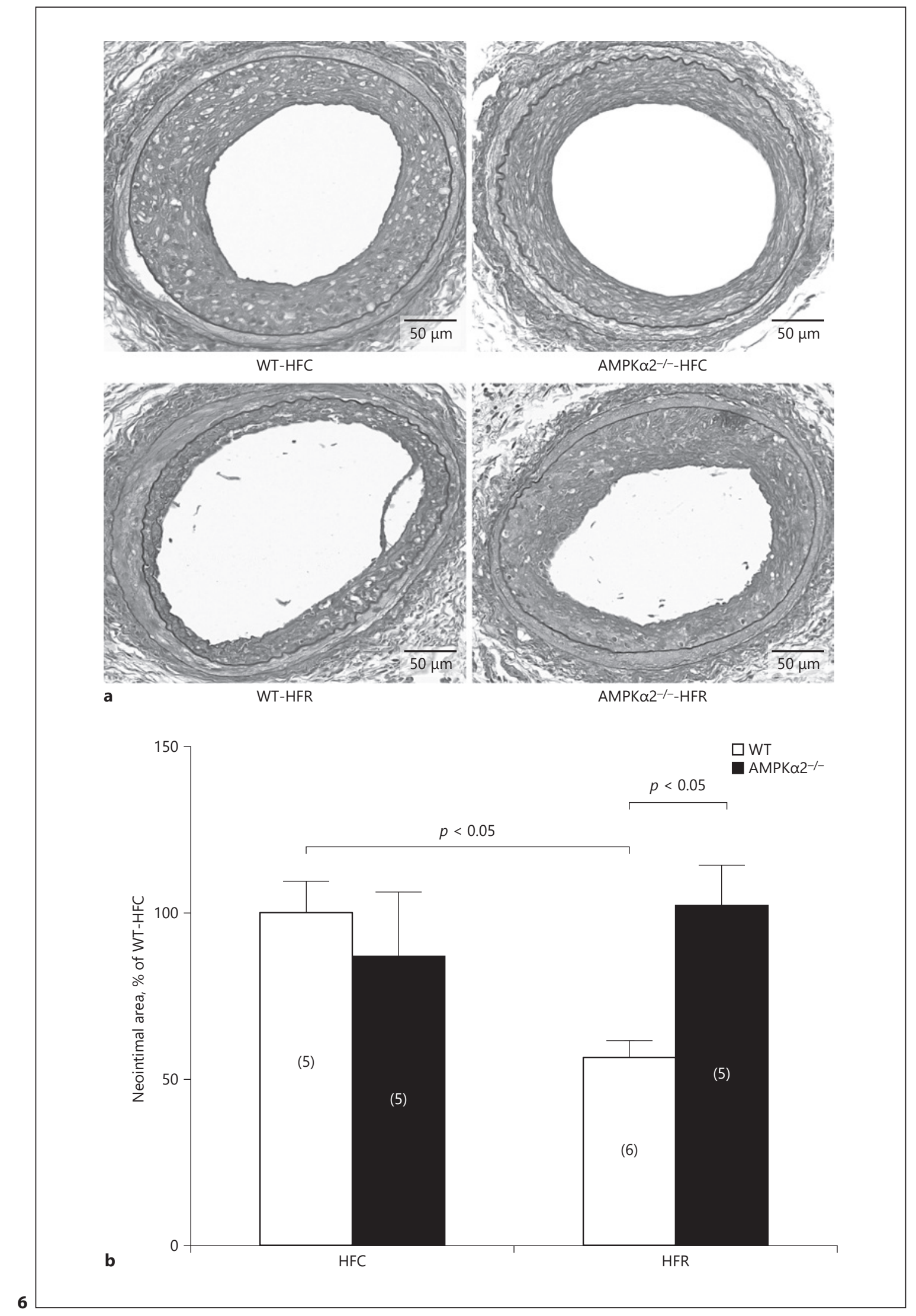

(For legend see next page.) 
on the effect of RSV, not on that of insulin, we did not determine whether the high-fat feeding-induced attenuation of the effect of insulin to decrease neointimal growth that we found in rats [6] is also confirmed in the mouse model.

AMPK has been shown to play an important role in the response to arterial injury. For example, the endothelial-specific overexpression of constitutively active AMPKa1 in mice can decrease neointimal hyperplasia, as well as enhance re-endothelialization and endothelial progenitor cell mobilization after arterial injury [36]. AMPKa2-null mice develop exacerbated neointimal area and intimal cell proliferation after arterial injury [37]. Unlike the aforementioned study in AMPKa2-null mice, we did not find differences related to genotype in the absence of RSV treatment, which may be explained by the different diet (high-fat diet in our study vs. chow-diet in the other study) and/or vessel injured (femoral artery collected 4 weeks after wire injury in our study vs. carotid artery collected 2 weeks after wire injury in the oth-

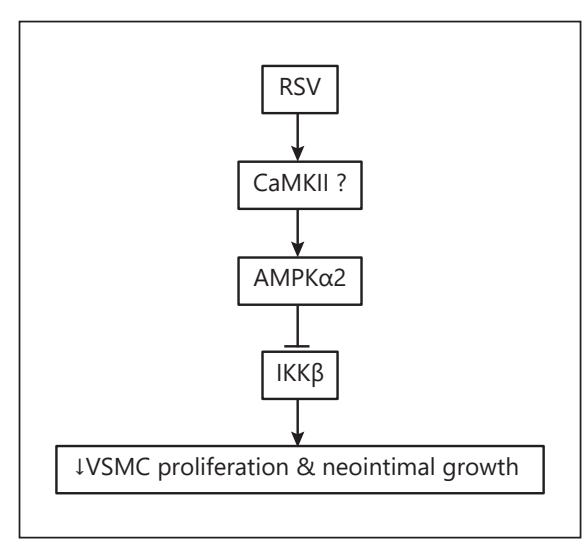

Fig. 7. Scheme of the postulated effect of resveratrol to decrease neointimal growth in high-fat-fed rodents. RSV, resveratrol; CAMKII, calcium/calmodulin-dependent protein kinase II; AMPK $\alpha 2$, AMP-activated kinase ( $\alpha 2$ isoform); IKK $\beta$, IкB kinase $\beta$; VSMC, vascular smooth muscle cell.

Fig. 6. The effect of resveratrol (RSV) on neointimal area in AMPKa2-null and wild-type controls. Representative images $(\times 200)$ (a) and quantification of neointimal area (b) of femoral artery cross sections measured at 28 days after wire injury in AMPKa2-null (AMPKa2 $2^{--}$) or wild-type (WT) littermates (C57BL/6 background) fed either high-fat diet (HFC) or RSV-supplemented high-fat diet (HFR). Numbers in parentheses represent mouse number. $p<0.05$ WT-HFR versus WT-HFC and WT-HFR versus KO-HFR (post hoc Bonferroni's test after a significant interaction between RSV and genotype was found).

The Effects of Resveratrol in Rodent Models of Restenosis er study) [37]. This latter study has shown that upregulation of NFKB by AMPKa2 deletion results in upregulation of $\mathrm{p} 27^{\mathrm{Kip} 1}$, a cyclin kinase inhibitor, thus increasing VSMC proliferation and intimal hyperplasia. Notably, in

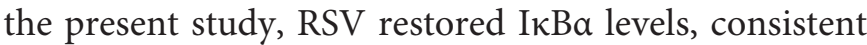
with downregulation of the NFkB pathway. Thus, AMPK activation by RSV may decrease neointimal growth via an anti-inflammatory effect. Since the effect of RSV on neointimal growth paralleled its effect to increase AMPK and Akt phosphorylation as well as whole-body insulin sensitivity, we cannot exclude that increased vessel insulin sensitivity may have contributed to the effect of RSV via AMPK. However, we have unpublished data that in models of selective vascular insulin resistance, the vessel response to insulin treatment is diminished, but neointimal growth is unaffected in the absence of exogenous insulin.

The present study raises the question of how RSV activates AMPK, since SIRT1 did not play a causal role in the effect of RSV on neointimal growth and eNOS, which may activate AMPK [52], also does not appear to be involved. In our previous study, we have shown that not all AMPK activators decrease neointimal growth, and in particular, metformin, which activates AMPK via increasing the AMP/ATP ratio, is ineffective [12]. RSV can activate AMPK via a similar mechanism; however, studies using high doses of RSV $(50-3,000 \mu \mathrm{m})$ in myotubes show that it can also activate AMPK via inhibiting phosphodiesterases. More specifically, the resulting elevation of cAMP activates Epac1 [33], which can subsequently activate CaMKII [53]. In addition, RSV has pleiotropic effects on calcium signaling [54] and an increase in intracellular calcium [55] would activate CAMKII. CaMKII is a known eNOS kinase [56], and it can also activate AMPK via CaMKK $\beta$ [33]. Thus, there is indirect in vitro evidence that RSV could activate both eNOS and AMPK via CaMKII. The known effect of CaMKII on neointimal growth appears to be isoform dependent as CaMKII $\delta$ was reported to aggravate neointimal hyperplasia [57, 58], while CaMKII $\gamma$ was reported to decrease it [59]. In turn, in vivo exposure to RSV has been reported to either activate [60] or inhibit CAMKII [61], and the isoform targeted by RSV is unknown. Irrespective of how RSV activates AMPK, it does so in injured arteries [14], whereas metformin does not [12], and the present study shows AMPK activation is causal for RSV protection against neointimal growth, which may be mediated by the antiinflammatory effect of AMPK (Fig. 7).

Further studies will have to be performed to disentangle the effect of CAMKII and AMPK and their relation- 
ship to eNOS in the effect of RSV to decrease neointimal growth. In summary, the present study demonstrated that RSV decreased neointimal area in rats fed a high-fat diet, a model resistant to the "anti-restenotic" effect of insulin. Second, RSV also decreased neointimal area in mice fed a high-fat diet, an effect not mediated via SIRT1 catalytic activity and likely also not by other effects of SIRT1 but dependent on AMPKa2.

\section{Acknowledgements}

The authors thank Liwei Zhou and Xuefei Liu for help in experiments and manuscript editing, respectively. We are also indebted to Milan Ganguly and Vivian Bradaschia from the Toronto Centre of Phenogenomics, Mt. Sinai Hospital, for performing the immunohistochemistry studies and to Loretta Lam and Yao-Fang Tan for general technical support.

\section{Statement of Ethics}

All procedures followed the Canada Council of Animal Care standards and were approved by the Animal Care Committee of the University of Toronto.

\section{Conflict of Interest Statement}

The authors have no conflicts of interest to declare.

\section{Funding Sources}

Funding provided by grants to A.G. from the Heart and Stroke Foundation of Canada (Grants \#T-7342, \#G-13-0001610, and G-18-0022151). J.G. and D.M.B. were supported by Banting and Best Diabetes Centre/Novo Nordisk Studentships, Heart \& Stroke Foundation of Ontario Graduate Scholarships, Ontario Graduate Scholarships, and Canadian Diabetes Association Doctoral Student Research Awards. J.G. was also a member of the Cardiovascular Sciences Collaborative Programs. Y.M. was supported by Showa University Research Grant for Young Researchers.

\section{Author Contributions}

J.G., T.J.P., D.M.B., and H.Z. acquired and analyzed data. Y.M., P.S.D., and M.G.M. analyzed data. A.G. conceived the work. D.F.M., M.W.M., S.P.H., E.L.T., and V.W.D. contributed to the conception of the work. J.G. and A.G. drafted the work, and all the other authors revised it critically. All authors gave final approval and agreed to be accountable for their work.

\section{References}

1 Alberti KG, Eckel RH, Grundy SM, Zimmet PZ, Cleeman JI, Donato KA, et al. Harmonizing the metabolic syndrome: a joint interim statement of the International Diabetes Federation Task Force on Epidemiology and Prevention; National Heart, Lung, and Blood Institute; American Heart Association; World Heart Federation; International Atherosclerosis Society; and International Association for the Study of Obesity. Circulation. 2009; 120(16):1640-5.

2 Howard G, O'Leary DH, Zaccaro D, Haffner S, Rewers M, Hamman R, et al. Insulin sensitivity and atherosclerosis. The Insulin Resistance Atherosclerosis Study (IRAS) Investigators. Circulation. 1996;93(10):1809-17.

3 Osanai H, Kanayama H, Miyazaki Y, Fukushima A, Shinoda M, Ito T. Usefulness of enhanced insulin secretion during an oral glucose tolerance test as a predictor of restenosis after direct percutaneous transluminal coronary angioplasty during acute myocardial infarction in patients without diabetes mellitus. Am J Cardiol. 1998;81(6):698-701.

4 Wang CC, Gurevich I, Draznin B. Insulin affects vascular smooth muscle cell phenotype and migration via distinct signaling pathways. Diabetes. 2003;52(10):2562-9.

5 Xi XP, Graf K, Goetze S, Hsueh WA, Law RE. Inhibition of MAP kinase blocks insulin-mediated DNA synthesis and transcrip- tional activation of c-fos by Elk-1 in vascular smooth muscle cells. FEBS Lett. 1997; 417(3):283-6.

6 Kim T, Chan KK, Suen R, Huynh N, Dhaliwall $\mathrm{J}$, Uchino $\mathrm{H}$, et al. Anti-atherogenic effect of insulin in vivo. J Vasc Res. 2005;42:455-62.

7 Breen DM, Dhaliwall JK, Chan KK, Guo J, Lam L, Bendeck MP, et al. Insulin inhibits and oral sucrose increases neointimal growth after arterial injury in rats. J Vasc Res. 2010;47(5): 412-22.

8 Breen DM, Chan KK, Dhaliwall JK, Ward MR, Al Koudsi N, Lam L, et al. Insulin increases reendothelialization and inhibits cell migration and neointimal growth after arterial injury. Arterioscler Thromb Vasc Biol. 2009;29(7):1060-6.

9 Chiang S, Breen DM, Guo J, Mori Y, Giacca A. Local insulin application on the carotid artery inhibits neointima formation. Can J Physiol Pharmacol. 2013;91(12):1086-94.

10 Guo J, Dhaliwall JK, Chan KK, Ghanim H, Al Koudsi N, Lam L, et al. In vivo effect of insulin to decrease matrix metalloproteinase- 2 and -9 activity after arterial injury. J Vasc Res. 2013; 50(4):279-88.

11 Guo J, Breen DM, Pereira TJ, Dalvi PS, Zhang $\mathrm{H}$, Mori $\mathrm{Y}$, et al. The effect of insulin to decrease neointimal growth after arterial injury is endothelial nitric oxide synthase-dependent. Atherosclerosis. 2015;241(1):111-20.
12 Guo J, Pereira TJ, Dalvi P, Yeung LS, Swain N, Breen DM, et al. High-dose metformin (420 $\mathrm{mg} / \mathrm{kg}$ daily p.o.) increases insulin sensitivity but does not affect neointimal thickness in the rat carotid balloon injury model of restenosis. Metabolism. 2017;68:108-18.

13 Tome-Carneiro J, Larrosa M, Yanez-Gascon MJ, Davalos A, Gil-Zamorano J, Gonzalvez $\mathrm{M}$, et al. One-year supplementation with a grape extract containing resveratrol modulates inflammatory-related microRNAs and cytokines expression in peripheral blood mononuclear cells of type 2 diabetes and hypertensive patients with coronary artery disease. Pharmacol Res. 2013;72:69-82.

14 Breen DM, Dolinsky VW, Zhang H, Ghanim $\mathrm{H}$, Guo J, Mroziewicz M, et al. Resveratrol inhibits neointimal formation after arterial injury through an endothelial nitric oxide synthase-dependent mechanism. Atherosclerosis. 2012;222(2):375-81.

$15 \mathrm{Gu}$ J, Wang CQ, Fan HH, Ding HY, Xie XL, $\mathrm{Xu} \mathrm{YM}$, et al. Effects of resveratrol on endothelial progenitor cells and their contributions to reendothelization in intima-injured rats. J Cardiovasc Pharmacol. 2006;47:711-21.

16 Khandelwal AR, Hebert VY, Dugas TR. Essential role of ER-alpha-dependent NO production in resveratrol-mediated inhibition of restenosis. Am J Physiol Heart Circ Physiol. 2010;299(5):H1451-8. 
17 Khandelwal AR, Hebert VY, Kleinedler JJ, Rogers LK, Ullevig SL, Asmis R, et al. Resveratrol and quercetin interact to inhibit neointimal hyperplasia in mice with a carotid injury. J Nutr. 2012;142(8):1487-94.

18 Kleinedler JJ, Foley JD, Orchard EA, Dugas TR. Novel nanocomposite stent coating releasing resveratrol and quercetin reduces neointimal hyperplasia and promotes re-endothelialization. J Control Release. 2012;159(1): 27-33.

19 Yurdagul A Jr., Kleinedler JJ, McInnis MC, Khandelwal AR, Spence AL, Orr AW, et al. Resveratrol promotes endothelial cell wound healing under laminar shear stress through an estrogen receptor-alpha-dependent pathway. Am J Physiol Heart Circ Physiol. 2014;306(6): H797-806.

20 Zhang J, Chen J, Yang J, Xu CW, Pu P, Ding $\mathrm{JW}$, et al. Resveratrol attenuates oxidative stress induced by balloon injury in the rat carotid artery through actions on the ERK1/2 and NF-kappa B pathway. Cell Physiol Biochem. 2013;31(2-3):230-41.

21 Zhang J, Chen J, Xu C, Yang J, Guo Q, Hu Q, et al. Resveratrol inhibits phenotypic switching of neointimal vascular smooth muscle cells after balloon injury through blockade of Notch pathway. J Cardiovasc Pharmacol. 2014;63(3):233-9.

22 Zou J, Huang Y, Cao K, Yang G, Yin H, Len J, et al. Effect of resveratrol on intimal hyperplasia after endothelial denudation in an experimental rabbit model. Life Sci. 2000;68(2): $153-63$.

23 Sun C, Zhang F, Ge X, Yan T, Chen X, Shi X, et al. SIRT1 improves insulin sensitivity under insulin-resistant conditions by repressing PTP1B. Cell Metab. 2007;6(4):307-19.

24 Pereira S, Park E, Moore J, Faubert B, Breen DM, Oprescu AI, et al. Resveratrol prevents insulin resistance caused by short-term elevation of free fatty acids in vivo. Appl Physiol Nutr Metab. 2015;40(11):1129-36.

25 Beher D, Wu J, Cumine S, Kim KW, Lu SC, Atangan L, et al. Resveratrol is not a direct activator of SIRT1 enzyme activity. Chem Biol Drug Des. 2009;74(6):619-24.

26 Dai H, Kustigian L, Carney D, Case A, Considine T, Hubbard BP, et al. SIRT1 activation by small molecules: kinetic and biophysical evidence for direct interaction of enzyme and activator. J Biol Chem. 2010;285(43):32695703.

27 Pacholec M, Bleasdale JE, Chrunyk B, Cunningham D, Flynn D, Garofalo RS, et al. SRT1720, SRT2183, SRT1460, and resveratrol are not direct activators of SIRT1. J Biol Chem. 2010;285(11):8340-51.

28 Mattagajasingh I, Kim CS, Naqvi A, Yamamori T, Hoffman TA, Jung SB, et al. SIRT1 promotes endothelium-dependent vascular relaxation by activating endothelial nitric oxide synthase. Proc Natl Acad Sci U S A. 2007; 104(37):14855-60.
29 Li L, Zhang HN, Chen HZ, Gao P, Zhu LH, Li HL, et al. SIRT1 acts as a modulator of neointima formation following vascular injury in mice. Circ Res. 2011;108(10):1180-9.

30 Bae JU, Lee SJ, Seo KW, Kim YH, Park SY, Bae SS, et al. SIRT1 attenuates neointima formation by inhibiting HIF-1alpha expression in neointimal lesion of a murine wire-injured femoral artery. Int J Cardiol. 2013;168(4): 4393-6.

31 Fullerton MD, Steinberg GR. SIRT1 takes a backseat to AMPK in the regulation of insulin sensitivity by resveratrol. Diabetes. 2010; 59(3):551-3.

32 Dasgupta B, Milbrandt J. Resveratrol stimulates AMP kinase activity in neurons. Proc Natl Acad Sci U S A. 2007;104(17):7217-22.

33 Park SJ, Ahmad F, Philp A, Baar K, Williams $\mathrm{T}$, Luo H, et al. Resveratrol ameliorates agingrelated metabolic phenotypes by inhibiting cAMP phosphodiesterases. Cell. 2012;148(3): 421-33.

34 Zheng J, Ramirez VD. Inhibition of mitochondrial proton F0F1-ATPase/ATP synthase by polyphenolic phytochemicals. $\mathrm{Br} \mathrm{J}$ Pharmacol. 2000;130(5):1115-23.

35 Morrow VA, Foufelle F, Connell JM, Petrie JR, Gould GW, Salt IP. Direct activation of AMP-activated protein kinase stimulates nitric-oxide synthesis in human aortic endothelial cells. J Biol Chem. 2003;278(34):3162939.

36 Li FY, Lam KS, Tse HF, Chen C, Wang Y, Vanhoutte PM, et al. Endothelium-selective activation of AMP-activated protein kinase prevents diabetes mellitus-induced impairment in vascular function and reendothelialization via induction of heme oxygenase- 1 in mice. Circulation. 2012;126(10):1267-77.

37 Song $\mathrm{P}$, Wang $\mathrm{S}$, He C, Wang S, Liang B, Viollet B, et al. AMPKalpha2 deletion exacerbates neointima formation by upregulating Skp2 in vascular smooth muscle cells. Circ Res. 2011;109(11):1230-9.

38 Seifert EL, Caron AZ, Morin K, Coulombe J, $\mathrm{He} \mathrm{XH}$, Jardine K, et al. SirT1 catalytic activity is required for male fertility and metabolic homeostasis in mice. FASEB J. 2012;26(2): 555-66.

39 Ghosh HS, Spencer JV, Ng B, McBurney MW, Robbins PD. Sirt1 interacts with transducinlike enhancer of split-1 to inhibit nuclear factor kappaB-mediated transcription. Biochem J. 2007;408(1):105-11.

40 Pfister JA, Ma C, Morrison BE, D’Mello SR Opposing effects of sirtuins on neuronal survival: SIRT1-mediated neuroprotection is independent of its deacetylase activity. PLoS One. 2008;3(12):e4090.

41 McBurney MW, Yang X, Jardine K, Hixon M, Boekelheide K, Webb JR, et al. The mammalian SIR2alpha protein has a role in embryogenesis and gametogenesis. Mol Cell Biol. 2003;23(1):38-54.
42 Chen SJ, Li H, Durand J, Oparil S, Chen YF. Estrogen reduces myointimal proliferation after balloon injury of rat carotid artery. Circulation. 1996;93(3):577-84.

43 Caron AZ, He X, Mottawea W, Seifert EL, Jardine $\mathrm{K}$, Dewar-Darch D, et al. The SIRT1 deacetylase protects mice against the symptoms of metabolic syndrome. FASEB J. 2014; 28(3):1306-16.

44 Purushotham A, Xu Q, Li X. Systemic SIRT1 insufficiency results in disruption of energy homeostasis and steroid hormone metabolism upon high-fat-diet feeding. FASEB J. 2012;26(2):656-67.

45 Fujii N, Ho RC, Manabe Y, Jessen N, Toyoda T, Holland WL, et al. Ablation of AMP-activated protein kinase alpha 2 activity exacerbates insulin resistance induced by high-fat feeding of mice. Diabetes. 2008;57(11):2958-66.

46 Mori Y, Chiang S, Bendeck MP, Giacca A. Insulin decreases atherosclerotic plaque burden and increases plaque stability via nitric oxide synthase in apolipoprotein E-null mice. Am J Physiol Endocrinol Metab. 2016;311:E335-45.

47 Jukema JW, Verschuren JJ, Ahmed TA, Quax PH. Restenosis after PCI. Part 1: pathophysiology and risk factors. Nat Rev Cardiol. 2011; 9(1):53-62.

48 Rivera L, Moron R, Zarzuelo A, Galisteo M. Long-term resveratrol administration reduces metabolic disturbances and lowers blood pressure in obese Zucker rats. Biochem Pharmacol. 2009;77(6):1053-63.

49 Gambini J, Ingles M, Olaso G, Lopez-Grueso R, Bonet-Costa V, Gimeno-Mallench L, et al. Properties of resveratrol: in vitro and in vivo studies about metabolism, bioavailability, and biological effects in animal models and humans. Oxid Med Cell Longev. 2015;2015: 837042.

50 Timmers S, Konings E, Bilet L, Houtkooper $\mathrm{RH}$, van de WT, Goossens GH, et al. Calorie restriction-like effects of 30 days of resveratrol supplementation on energy metabolism and metabolic profile in obese humans. Cell Metab. 2011;14(5):612-22.

51 Zhang QJ, Holland WL, Wilson L, Tanner JM, Kearns D, Cahoon JM, et al. Ceramide mediates vascular dysfunction in diet-induced obesity by PP2A-mediated dephosphorylation of the eNOS-Akt complex. Diabetes. 2012;61(7):1848-59.

52 Deshmukh AS, Long YC, de Castro BT, Karlsson HK, Glund S, Zavadoski WJ, et al. Nitric oxide increases cyclic GMP levels, AMP-activated protein kinase (AMPK)alpha1-specific activity and glucose transport in human skeletal muscle. Diabetologia. 2010;53(6):114250.

53 Pereira L, Metrich M, Fernandez-Velasco M, Lucas A, Leroy J, Perrier R, et al. The cAMP binding protein Epac modulates Ca2+ sparks by a Ca2+/calmodulin kinase signalling pathway in rat cardiac myocytes. J Physiol. 2007; 583(Pt 2):685-94.
The Effects of Resveratrol in Rodent Models of Restenosis
J Vasc Res 2020;57:325-340

DOI: $10.1159 / 000509217$ 
54 McCalley AE, Kaja S, Payne AJ, Koulen P. Resveratrol and calcium signaling: molecular mechanisms and clinical relevance. Molecules. 2014;19(6):7327-40.

55 Peterson JA, Oblad RV, Mecham JC, Kenealey JD. Resveratrol inhibits plasma membrane $\mathrm{Ca}(2+)$-ATPase inducing an increase in cytoplasmic calcium. Biochem Biophys Rep. 2016; 7:253-8.

56 Kobayashi T, Nemoto S, Ishida K, Taguchi K, Matsumoto T, Kamata K. Involvement of CaM kinase II in the impairment of endothelial function and eNOS activity in aortas of type 2 diabetic rats. Clin Sci. 2012;123(6): $375-86$.
57 House SJ, Singer HA. CaMKII-delta isoform regulation of neointima formation after vascular injury. Arterioscler Thromb Vasc Biol. 2008;28(3):441-7.

58 Li W, Li H, Sanders PN, Mohler PJ, Backs J, Olson EN, et al. The multifunctional $\mathrm{Ca} 2+l$ calmodulin-dependent kinase II delta (CaMKIIdelta) controls neointima formation after carotid ligation and vascular smooth muscle cell proliferation through cell cycle regulation by p21. J Biol Chem. 2011;286(10):7990-9.

59 Saddouk FZ, Sun LY, Liu YF, Jiang M, Singer DV, Backs J, et al. Ca2+/calmodulin-dependent protein kinase II-gamma (CaMKIIgamma) negatively regulates vascular smooth muscle cell proliferation and vascular remodeling. FASEB J. 2016;30(3):1051-64.
60 Shi DD, Dong CM, Ho LC, Lam CTW, Zhou $\mathrm{XD}, \mathrm{Wu} \mathrm{EX}$, et al. Resveratrol, a natural polyphenol, prevents chemotherapy-induced cognitive impairment: involvement of cytokine modulation and neuroprotection. Neurobiol Dis. 2018;114:164-73.

61 Lin X, Cheng C, Zhong J, Liu B, Luo C, Ou W, et al. Resveratrol inhibits angiotensin IIinduced proliferation of A7r5 cells and decreases neointimal hyperplasia by inhibiting the CaMKIIHDAC4 signaling pathway. Mol Med Rep. 2018;18(1):1007-14. 